\title{
Industrial method of decontamination of dimethoate containing wastewater
}

\author{
Volodymyr Vasylenko ${ }^{1 *}$, Marina Sidorenko ${ }^{1}$, and Saulius Mickevičius ${ }^{1}$ \\ ${ }^{1}$ Vytautas Magnus University, Faculty of Natural Sciences, Universiteto g. 10-314, 53361, \\ Akademija, Kauno raj., Lithuania
}

\begin{abstract}
The problem of wastewater disposal affects not only third countries, but also world giants such as China or the United States of America. The European Union and the Commonwealth of Independent States are no exception. The increasing use of organophosphate pesticides requires the search for new, more efficient and cheaper ways to dispose of their residual amounts. The existing methods of disposal of toxic waste are costly, ineffective, and environmentally hazardous. The optimal solution can be a chemical system for decontamination of wastewater directly at the place of their origin, for example, at the production of pesticide formulations and agro-industrial facilities. This article presents the results of studying the effectiveness of the chemical system for the destruction of organophosphorus compounds based on hydrogen peroxide and potassium hydroxide in relation to dimethoate. The results of the scaling of the decontamination process are presented and an installation for the technological process of wastewater disposal is proposed. The research results show a high reactivity of the system under study and a high efficiency level of the described technological process.
\end{abstract}

\section{Introduction}

Food supply is one of the key humanitarian problems. This challenge is faced not only by the third world countries, but also by the world's densely populated giants such as the People's Republic of China and the states of the Arabian Peninsula. The countries of the European Union and the Commonwealth of Independent States were no exception. The food problem primarily concerns the quality of drinking water and primary agricultural products, namely cereals and legumes. Pesticides are used to protect the latter, which are strategically important resources. These substances are used to combat insects, molds, weeds, and other pests.

The uncontrolled use of plant protection products has led to a completely opposite effect. Qualitative soil degradation and reduced yield, reduced safety and nutritional value of plant products, pollution of river water areas - all these examples are the consequences of irrational use of pesticide formulations. The compounds used differ in their structure and chemical properties. They are able to influence a person both through food resources and through direct

\footnotetext{
*Corresponding author: volodymyr.vasylenko@,vdu.lt
} 
contact [1]. Of particular concern are pesticides that have been deemed obsolete by the Food and Agriculture Organization of the United Nations. Thus, organochlorine pesticides are almost completely phased out in the territory of the Organization of the United Nations. Remains of such pesticides at landfills and the increasing use of plant protection products of organophosphate nature remain a problem (Fig. 1) [2,3]. The world leaders in the use of pesticides are the People's Republic of China and the United States of America, and in the European Union - France and Italy (Fig. 2) [3].

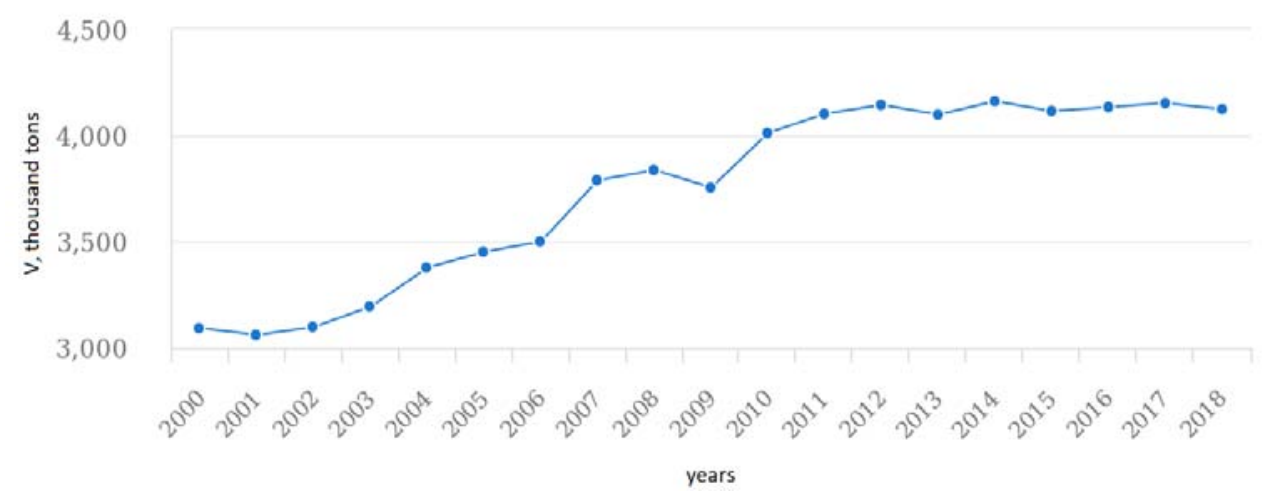

Fig. 1. General statistics on the use of pesticide formulations.

Organophosphorus compounds have a significant toxic effect (Table 1) [4]. Mainly due to the ability to inhibit acetylcholinesterase and cause acute, potentially fatal conditions and neurological disorders. Despite this, they are actively used in many industries. Organophosphates are used not only in agriculture, but also in other areas. For example, as ligands in catalytic reactions with transition metals or in pharmacology, research is underway on the use of organophosphorus compounds in the treatment of osteoporosis, as antineoplastic molecules, as antiviral drugs. It is important to note that the main problem remains the problem of utilization or decontamination of residual amounts of pesticides after their industrial use. So, for example, in the production of pesticide formulations, huge volumes of wastewater are formed after washing of technological equipment, and the volumes of production and sale of such compositions are steadily growing (Fig. 3) [3]. The situation is the same with other industries.

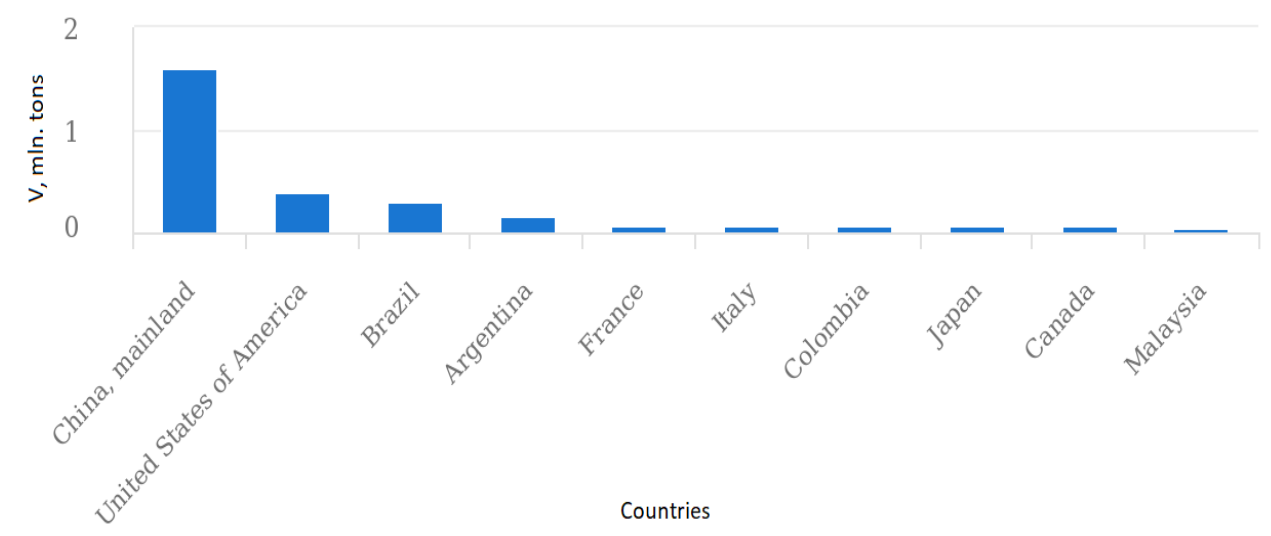

Fig. 2. Statistics on the use of pesticide formulations by countries. 
Table 1. Dimethoate toxicity.

\begin{tabular}{|c|c|c|c|}
\hline Species & Test & $\begin{array}{c}\text { Duration and } \\
\text { conditions }\end{array}$ & Result \\
\hline Rat, sex notstated & Acute oral toxicity & $\begin{array}{c}\text { Not stated, purity not } \\
\text { stated }\end{array}$ & LD $_{50}=310 \mathrm{mg} / \mathrm{kg} \mathrm{bw}$ \\
\hline Rat, sex notstated & $\begin{array}{c}\text { Acute dermal } \\
\text { toxicity }\end{array}$ & $\begin{array}{c}\text { Not stated, purity not } \\
\text { stated }\end{array}$ & LD $_{50}>7000 \mathrm{mg} / \mathrm{kg} \mathrm{bw}$ \\
\hline Rabbit, sex notstated & Dermal irritation & $\begin{array}{c}\text { Not stated, purity not } \\
\text { stated }\end{array}$ & Slightly irritating \\
\hline Rabbit, sex notstated & Eye irritation & $\begin{array}{c}\text { Not stated, purity not } \\
\text { stated }\end{array}$ & Slightly irritating \\
\hline Human, sexnot stated & $\begin{array}{c}\text { Dermal } \\
\text { sensitization }\end{array}$ & $\begin{array}{c}\text { Not stated, purity not } \\
\text { stated }\end{array}$ & Positive \\
\hline \multicolumn{2}{|c|}{ Long-term toxicity and carcinogenicity $(1$ year) } \\
\hline Rat, sex notstated & Oral & $\begin{array}{c}\text { Repeated dosing, } \\
\text { toxicityand } \\
\text { carcinogenicity }\end{array}$ & $\begin{array}{c}\text { NOAEL }=0.04 \mathrm{mg} / \mathrm{kg} \text { per day, } \\
\text { cholinesterase inhibition. No } \\
\text { evidence ofcarcinogenicity. }\end{array}$ \\
\hline
\end{tabular}

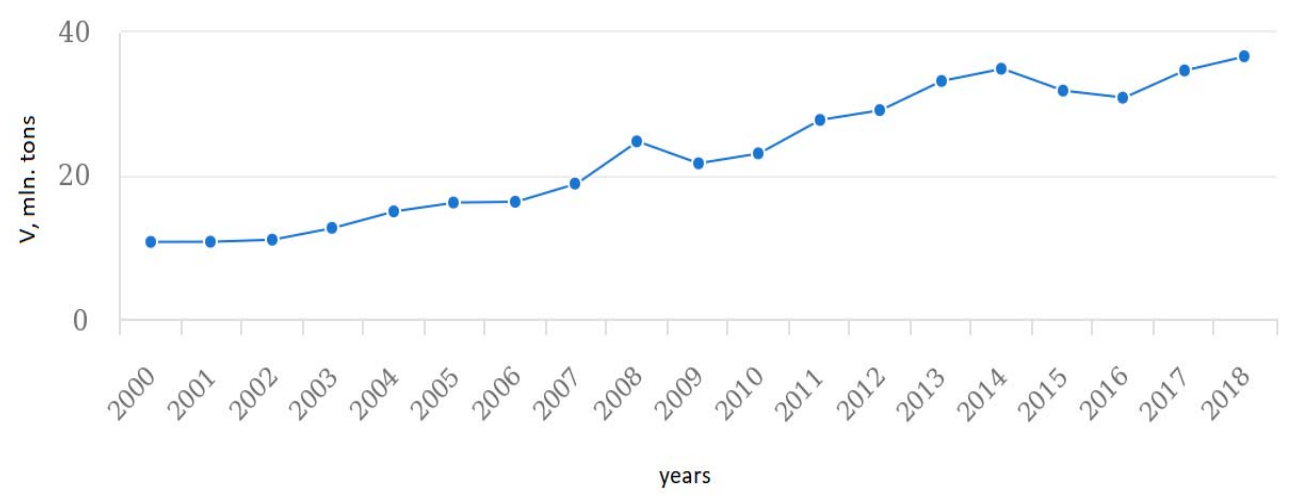

Fig. 3. Export value of pesticides.

After the manufacture of pesticide products and their used, part of the pesticides remain in containers and equipment. These residues are removed by flushing with water, resulting in toxic waste water that can adversely affect people, domestic animals, livestock and wild animals [5-7]. A low concentration, around $3000 \mathrm{ppm}$, is insufficient for acute human poisoning through short-term contact (except for ingestion) but is a threat to the environment. Such concentrations have a detrimental effect on flora and fauna, besides, lead to chronic poisoning of the population. Modern methods of disposal of hazardous waste are costly and ineffective. Residual products are often more toxic than the original components. For example, the dimethoate when heated isomerized to more toxic volatile compounds. Wherein, the main method of its disposal is thermal decomposition. Also, there are other problems associated with the destruction of highly hazardous substances of this kind: collection, storage and transportation. It is necessary to introduce more efficient and less costly methods of decontamination of residual quantities of pesticides, including in wastewater.

The existing methods of decontamination of waste contaminated with pesticides are feasible only at specialized enterprises. Such enterprises have at their disposal appropriate 
incineration facilities, polygons and certified personnel. Consequently, decontamination of pesticide residues cannot be applied directly in factories. The volume of such waste is quite large and is a significant cost item for the respective enterprises.

Therefore, the development and selection of safe disposal / processing methods for agricultural pesticides is of paramount importance [8].

The aim of the research is to develop a method for industrial utilization of rinsing water contaminated with pesticides and / or to significantly reduce the volume of utilized waste. The developed method can be easily implemented directly at enterprises engaged in the production of pesticide formulations and warehouses for the collection of liquid residues of such products. The widespread use of the developed technological scheme will lead to a decrease in disposal costs and reduce the load on landfills for the disposal of pesticides.

\section{Disposal methods for pesticides}

As already noted, the existing methods for the disposal of pesticide products have a number of significant disadvantages: the need for large areas of land for polygons, high cost, low efficiency. There are four modern cleaning methods: thermal, chemical, physical, biological [9]. Low-pollution pesticide decontamination methods such as land cultivation, disposal pits, evaporation ponds and landfills can be applied directly on the farm [10-14] (Table 2)

Table 2. Disadvantages of pesticide wastewater disposal methods [8].

\begin{tabular}{|c|c|}
\hline Method & Disadvantages \\
\hline Land Cultivation & Large area of land \\
& $\begin{array}{c}\text { Long decontamination time } \\
\text { Restrictions on the use of the land plot }\end{array}$ \\
\hline \multirow{2}{*}{ Disposal Pits } & Low rate of decontamination \\
& The need to use plots \\
& Weather dependence \\
\hline Evaporation Ponds & Low rate of decontamination \\
& The need to use plots \\
& Weather dependence \\
\hline Landfills & Large area of land \\
& High cost \\
\hline
\end{tabular}

Analysis of the general methods of utilization of wastewater contaminated with pesticides (Table 3) also confirms the need to develop a more efficient and economical method of their neutralization. Thermal methods for the destruction of toxic substances imply their combustion in the presence of oxygen (destruction at a temperature of $1000{ }^{\circ} \mathrm{C}$ in an oxygen atmosphere). Subsequently, water vapor, carbon dioxide, some volatile acids and carbon (ash) should be released. It is important that the decomposition of the substance occurs within 2 seconds $[15,16]$. The use of lower temperature conditions leads to the formation of toxic degradation products [17]. Even in the case of using the most effective thermal schemes for the disposal of pesticides, part of the degradation products (polyaromatic hydrocarbons, dioxins) can cause significant damage to the environment [18] or destruction may occur incompletely and part of the contaminant is released into the atmosphere [15]. This method is the most widespread in world practice, along with waste burial. 
Table 3. General pesticide disposal methods [8].

\begin{tabular}{|c|c|c|}
\hline Method & Description & Disadvantages \\
\hline Thermal & Pyrolysis of contaminated compositions & $\begin{array}{c}\text { High cost } \\
\text { Not eco-friendly } \\
\text { Not universal } \\
\text { Difficult to use }\end{array}$ \\
\hline Chemical & $\begin{array}{c}\text { Chemical destruction by degradation } \\
\text { reactions }\end{array}$ & $\begin{array}{c}\text { High cost } \\
\text { High variability of the result } \\
\text { Potential toxicity of derivates }\end{array}$ \\
\hline Physical & Adsorption and settling & $\begin{array}{c}\text { Lack of destruction of toxins } \\
\text { Availability of products for subsequent } \\
\text { disposal }\end{array}$ \\
\hline Biological & Destruction by bacteria & $\begin{array}{c}\text { High costs } \\
\text { High variability of the result } \\
\text { Low process speed }\end{array}$ \\
\hline
\end{tabular}

The use of chemical methods is based mainly on oxidation reactions or hydrolysis of pollutants. UV irradiation can be used to potentiate the ongoing reactions [14, 19-22]. High variability (the inconsistent efficiency) of the method and the complexity of the ongoing processes leads to the inability to predict the results of the reaction [14].

Effective physical methods of disposal of products contaminated with pesticides consist in the adsorption of polluting components by various types of inorganic [23,24] and organic $[25,26]$ sorbents. The most common adsorbent used in the purification of agrochemicals is activated carbon. It is important to remember that adsorbents have their own capacity and exceeding this threshold can lead to a reverse process. Also, the critical parameter is the concentration of the sorbed substance. Thus, N-phosphonomethylglycine upon adsorption on $\mathrm{MgAl}-\mathrm{LDH}$ can both be adsorbed and participate in ion exchange [27].

Pesticides can be metabolized by various types of aerobic and anaerobic bacteria [15]. The degradation of certain structures of pesticides should proceed under the influence of various types of microorganisms sequentially [28]. The effectiveness of these methods varies at the level of $33.1 \%-95.8 \%$ [29] and is the main disadvantage of such methods along with the low rate of the corresponding reactions.

It was shown [8] that a number of methods for the disinfection of contaminated compositions can be applied directly at the sites of their formation, although with insufficient efficiency. Other methods, due to cost, variability of effect and complexity in implementation, can only be used in specialized enterprises.

\section{The aim and objectives of the study}

The aim of this study is to approbation the industrial technology for decontamination of wastewater contaminated with dimethoate during the reaction of peroxide hydrolysis, which will make it possible to assess the possibility of using and the effectiveness of decontamination systems directly at the place of toxic waste generation (factories for the production of plant protection products).

The research objectives are:

- to investigate the effectiveness of the decontamination system for dimethoate using a model solution as an example; 
- scaling of the decontamination process at a laboratory facility.

\section{Materials and methods}

\subsection{Materials and equipment used in the experiment}

In this study were used dimethoate $98.3 \%$ (Sigma-Aldrich, Inc., Germany), 1Cetylpyridinium chloride monohydrate (Sigma-Aldrich, Inc., Germany), potassium hydroxide (Sigma-Aldrich, Inc., Germany), boric acid (Sigma- Aldrich, Inc., Germany), Acetonitrile for HPLC (Sigma-Aldrich, Inc., Germany), glacial acetic acid (Sigma-Aldrich, Inc., Germany), hydrogen peroxide 33\% aqueous solution (Sigma-Aldrich, Inc., Germany), a model preparation with a dimethoate content of $400 \mathrm{~g} / 1$ (formulation: concentrate emulsion).

To prepare the $\mathrm{pH}$ regulator of the mobile phase, glacial acetic acid was added to 1000 $\mathrm{ml}$ of deionized water until $\mathrm{pH}=3.5$. The mixing of the components of the mobile phase was carried out by programming the gradient flow in the software of the liquid chromatograph. A mixture of hydrogen peroxide with alkali was used within 5 hours after preparation based on existing research [30].

Laboratory glassware (NSlabbox, Spain), $\mathrm{pH}$ meter (Mettler Toledo, USA), water purification system (ADRONA Crystal, Latvia), magnetic stirrer (IDL, Germany), ultrasonic bath (BANDELIN, Germany), liquid chromatograph SCL- 40 (Shimadzu, Japan) with a PDA detector were used. LabSolutions software, single-channel automatic dispensers of 5-50 $\mu \mathrm{l}$ and 20-200 $\mu \mathrm{l}$, a timer, a stand for scaling up the technology of decontamination of wastewater containing dimethoate (like a Neibel reaction column) were used also.

\subsection{Decontamination systems for dimethoate}

The already known decontamination system and technique were used as a baseline during this study [30,31]. This methodology has not been tested for dimethoate. Its destruction was carried out by creating conditions for alkaline perhydrolysis when introducing peroxide anions into the system, as an $\alpha$-nucleophile, and activators of nucleophilic substitution, as well as the formation of micellar systems using surfactants.

The peroxide anion was added into the system in the form of hydrogen peroxide $\left(\mathrm{H}_{2} \mathrm{O}_{2}\right)(1)$ :

$$
\mathrm{H}_{2} \mathrm{O}_{2}+\mathrm{HO}^{-} \leftrightarrow \mathrm{HOO}^{-}+\mathrm{H}_{2} \mathrm{O}
$$

To form a micellar complex, cetylpyridinium chloride was included in the system as a detergent additive. Cetylpyridinium chloride has two significant advantages for inactivation systems for the inactivation of pesticide residues. Firstly, the cationic surfactant creates the necessary conditions for the nucleophilic reaction of the electrophilic centers of the contaminant. Secondly, cetylpyridinium chloride is one of the safest micelle-forming agents, which makes it possible to use it in all spheres of the chemical industry without exception.

According to existing research, hydrogen peroxide does not have significant oxidizing properties. To activate it, substances that activate hydrogen peroxide were added. As a result, peroxyacids with high reactivity are formed.

Previous studies have confirmed the effectiveness of boric acid as an activator of nucleophilic substitution [30]. The using of the boric acid as an activator, several activating compounds are formed. According to the scheme (2.1-2.4), each activating compound increases the rate of inactivation of the contaminated solution [27]. 


$$
\begin{aligned}
& \mathrm{B}(\mathrm{OH})_{3}+\mathrm{H}_{2} \mathrm{O} \leftrightarrow \mathrm{B}(\mathrm{OH})_{4}^{-}+\mathrm{H}^{-} \\
& \mathrm{B}(\mathrm{OH})_{4}^{-}+\mathrm{H}_{2} \mathrm{O}_{2} \leftrightarrow \mathrm{B}(\mathrm{OH})_{3}(\mathrm{OOH})^{-}+\mathrm{H}_{2} \mathrm{O} \\
& \mathrm{B}(\mathrm{OH})_{3}(\mathrm{OOH})^{-}+\mathrm{H}_{2} \mathrm{O}_{2} \leftrightarrow \mathrm{B}(\mathrm{OH})_{2}(\mathrm{OOH})_{2}^{-}+\mathrm{H}_{2} \mathrm{O} \\
& \mathrm{B}(\mathrm{OH})_{2}(\mathrm{OOH})_{2}^{-}+\mathrm{H}_{2} \mathrm{O}_{2} \leftrightarrow \mathrm{B}(\mathrm{OH})_{2}(\mathrm{OOH})+\mathrm{H}_{2} \mathrm{O}
\end{aligned}
$$

As a result, the system for decontamination is displayed in the following schema (3):

$$
\left(\mathrm{H}_{2} \mathrm{O}_{2}+\mathrm{HO}^{-}+\mathrm{HOO}^{-}\right) \mathrm{H}_{2} \mathrm{O}
$$

\subsection{Chromatographic method}

Control over the degradation of dimethoate was carried out using the method described in the CIPAC Handbook E MT 28 with minor adjustments to increase selectivity and separation for given system components.

Analytical column Kinetex ${ }^{\circledR} 5 \mu \mathrm{m}$ EVO C18 $100 \AA, 150 * 4.6 \mathrm{~mm}$ was used for analysis. The analysis conditions were as follows:

- $\quad$ Mobile phase: acetonitrile: water $(\mathrm{pH}=3.5)$ - 40:60 (v/v);

- flow rate: $1 \mathrm{~cm}^{3} / \mathrm{min}$

- solvent: not used (no need for extraction).

- column thermostat temperature: $40^{\circ} \mathrm{C}$;

- injector thermostat temperature: $20^{\circ} \mathrm{C}$;

- Injection volume: $5 \mu$;

- $\quad$ Detection: PDA, $\lambda=210 \mathrm{~nm}$;

- Dimethoate retention time: $4.7 \mathrm{~min}$;

- Chromatography time: $10.0 \mathrm{~min}$.

The detection and quantification limit of the method used according to validation tests is $4.5 \mathrm{ppm} 15 \mathrm{ppm}$, respectively.

Preparation of a standard solution (reference solution):

$25 \mathrm{mg}$ (accurately weighed) of dimethoate and $30 \mathrm{~cm}^{3}$ of the mobile phase were added in a volumetric flask of class A with a volume of $50.0 \mathrm{~cm}^{3}$. The flask was placed in an ultrasonic bath and sonicated for 2-3 minutes. Then the flasks were removed from the bath, kept for 510 minutes at ambient temperature, and the volume of the solution was brought up to the mark.

Suitability of the chromatographic system:

The RSD for 5 consecutive injections of the standard solution should not exceed 1.5\%. The number of theoretical plates for the dimethoate peak in the chromatogram of the standard solution is not less than 2100 . The obtained data were processed by general mathematical methods.

\subsection{Laboratory unit for scaling up the cleaning process}

Scaling up of the purification was carried out on a laboratory facility with a schematic diagram similar to an extraction column with alternating mixers and settling nozzles (Fig. 4). 


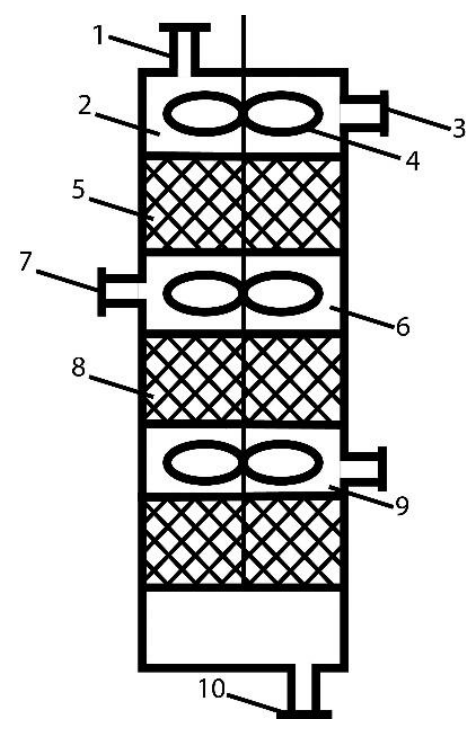

Fig. 4. Schema of a laboratory installation for cleaning rinsing water

\subsection{Preparation of a model solution}

A model solution, an emulsion concentrate with a dimethoate content of $400 \mathrm{~g} / \mathrm{l}$, was diluted to a concentration of $3000 \mathrm{ppm}(0.3 \%)$ using tap water by vigorous stirring on a magnetic stirrer without heating.

\subsection{The method for studying the effectiveness of a decontamination system}

The concentration of the model solution was detected preliminary. Five test solutions were prepared (Table 4). The concentration of dimethoate was determined sequentially in each of the test solutions for 180 minutes at intervals of 30 minutes. A control analysis was performed after 210 minutes.

Table 4. Composition of the test sample [31].

\begin{tabular}{|c|c|}
\hline Component & Content, $\mathbf{\%}, \mathbf{m} / \mathbf{m}$ \\
\hline Model solution & 82,00 \\
\hline Hydrogen peroxide & 3,00 \\
\hline Cetylpyridinium chloride & 3,85 \\
\hline Boric acid & 3,95 \\
\hline Potassium hydroxide & 7,20 \\
\hline
\end{tabular}

\subsection{The method for studying the effectiveness of a scale model}

In accordance with the description (p. 4.4), $5 \mathrm{~L}$ of the model solution were decontaminated using the amounts of system components indicated in Table 4. Sample selection and analysis of dimethoate content were carried out from chamber 8 (Fig. 4) at intervals of 60 minutes for 3 hours. To obtain reliable results, five consecutive tests are carried out. After neutralizing of the solution, the $\mathrm{pH}$ value was measured in the sample taken from the chamber 10. 


\section{Results}

\subsection{Study of the effectiveness of the decontamination system}

Two directions of the chemical reaction for the destruction of dimethoate were considered by modelling the system, perhydrolysis with the participation of the $\mathrm{HOO}^{-}$-anion and alkaline hydrolysis due to the $\mathrm{OH}^{-}$-anion.

Changes in concentration at the peak of dimethoate were monitored by high performance liquid chromatography with reanalysis of samples at intervals of 30 minutes.

Table 5. Changes in dimethoate concentration

\begin{tabular}{|c|c|c|c|c|c|c|}
\hline \multirow{3}{*}{ Exposure, min } & \multicolumn{5}{|c|}{ Test solution } & \multirow{3}{*}{$\begin{array}{c}\text { Average } \\
\text { concentration, } \\
\text { ppm }\end{array}$} \\
\hline & $-1-$ & $-2-$ & $-3-$ & $-4-$ & $-5-$ & \\
\hline & \multicolumn{5}{|c|}{ Concentration *, ppm } & \\
\hline 0 & 3000 & 3000 & 3000 & 3000 & 3000 & 3000 \\
\hline 30 & 784.3 & 760.1 & 734.8 & 721.2 & 778.6 & 765.1 \\
\hline 60 & 217.0 & 259.9 & 224.6 & 212.2 & 255.8 & 233.9 \\
\hline 90 & 69.3 & 65.1 & 69.2 & 64.4 & 67.2 & 67.0 \\
\hline 120 & 22.8 & 30.8 & 31.8 & 37.2 & 36.0 & 31.7 \\
\hline 150 & 19.5 & 17.3 & 20.4 & 29.2 & 20.0 & 21.3 \\
\hline 180 & 15.2 & 10.6 & 14.7 & 20.1 & 12.0 & 14.5 \\
\hline
\end{tabular}

* the concentration of dimethoate is reduced to the nominal $3000 \mathrm{ppm}$

The data in Table 5 indicate the rapid destruction of dimethoate in solution within 180 minutes to the limit of quantitative determination. An additional test established the concentration of dimethoate 210 minutes after the start of the reaction, which was $6 \mathrm{ppm}$ (below the limit of quantitative determination). Based on the data obtained by formula (4), the theoretical first-order reaction rate constants are calculated for each of the points under study (Fig. 5)

$$
k_{i}=\frac{1}{t} \times \ln \frac{C_{\infty}-C_{0}}{C_{\infty}-C_{t}}
$$

where $\mathrm{t}$ is the reaction time, $\mathrm{c} ; \mathrm{C} \infty$ - concentration of dimethoate after completion of the reaction, ppm; $\mathrm{C}_{0}$ - concentration of dimethoate before the start of the reaction, $\mathrm{ppm} ; \mathrm{C}_{\mathrm{t}}$ is the concentration of dimethoate at the specified time point, ppm.

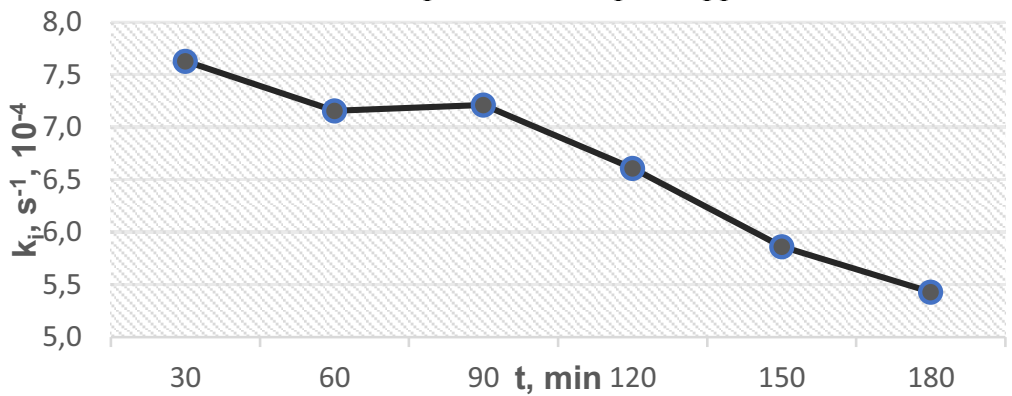

Fig. 5. Changes in the theoretical first-order reaction rate constant. 
According to the data obtained, the reaction rate constant decreases by $29 \%$. This result, combined with the extremely low concentration of dimethoate at the end of the reaction, indicates the potential efficiency of the system used throughout the decontamination process. To assess the effectiveness of the decontamination system according to formula (5), the second-order reaction rate constants were calculated for each point under study, taking into account the concentration of hydroxyl ions in the solution $[\mathrm{OH}-]=0.3 \mathrm{mmol} / \mathrm{L}(\mathrm{pH}=10.5)$ and hydrogen peroxide $\left[\mathrm{H}_{2} \mathrm{O}_{2}\right]=200 \mathrm{mmol} / \mathrm{l}$.

$$
k_{i}^{2}=\frac{k_{i}^{1}}{C_{i}}
$$

where $k_{i}^{1}$ is the first order reaction rate constant; $\mathrm{C}_{\mathrm{i}}$ is the concentration of the corresponding component, $\mathrm{mmol} / \mathrm{l}$.

The calculated values of the second order reaction rate constants are shown in Table 6.

Table 6. Rate constants of second-order reactions.

\begin{tabular}{|c|c|c|}
\hline Time, $\mathbf{m i n}$ & $\boldsymbol{k}_{\mathrm{OH}^{-}}^{\mathbf{2}}, \mathbf{1 0}^{-3}$ & $\boldsymbol{k}_{\mathrm{H}_{\mathbf{2}} \mathrm{O}_{2}}^{\mathbf{2}}, \mathbf{1 0}^{-\mathbf{6}}$ \\
\hline 30 & 2.54 & 3.81 \\
\hline 60 & 2.38 & 3.58 \\
\hline 90 & 2.40 & 3.61 \\
\hline 120 & 2.20 & 3.30 \\
\hline 150 & 1.95 & 2.93 \\
\hline 180 & 1.81 & 2.71 \\
\hline
\end{tabular}

In the case of the presence of two active components $\mathrm{OH}^{-}$and $\mathrm{H}_{2} \mathrm{O}_{2}$, the equation for the observed reaction rate constant takes the form (6) for calculating the observed reaction rate constant:

$$
k_{i}^{f}=k_{\mathrm{OH}^{-}}^{2} \times\left[\mathrm{OH}^{-}\right]+k_{\mathrm{H}_{2} \mathrm{O}_{2}}^{2} \times\left[\mathrm{H}_{2} \mathrm{O}_{2}\right],
$$

In this case, the data shown in Figure 3 acquire the following numerical values (Table 7) and visualization (Figure 6).

Table 7. Observed rate constants for first-order reactions.

\begin{tabular}{|c|c|}
\hline Time, $\boldsymbol{m i n}$ & $\boldsymbol{k}_{\boldsymbol{i}}^{\boldsymbol{f}}, \mathbf{s}^{\mathbf{- 1}}, \mathbf{1 0 ^ { - 3 }}$ \\
\hline 30 & 8.39 \\
\hline 60 & 7.87 \\
\hline 90 & 7.93 \\
\hline 120 & 7.27 \\
\hline 150 & 6.45 \\
\hline 180 & 5.97 \\
\hline
\end{tabular}




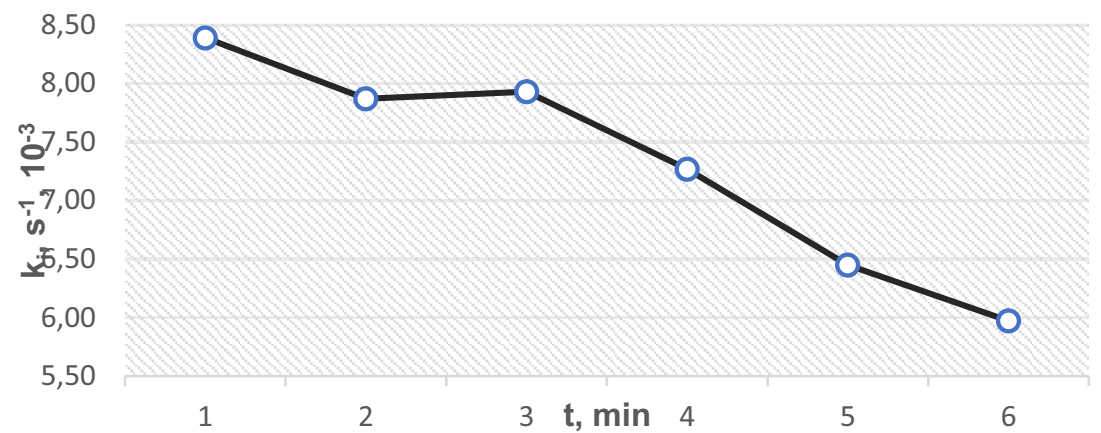

Fig. 6. Changes in the observed first-order reaction rate constant.

Based on the data obtained, it can be concluded that a decontamination system containing a hydroxide anion at a concentration of $0.3 \mathrm{mmol} / \mathrm{L}$ and hydrogen peroxide at a level of 200 $\mathrm{mmol} / \mathrm{L}$ is suitable for the destruction of dimethoate and does not lose its properties over time until the moment of almost complete destruction of pollutant.

The reliability of the data obtained is confirmed by the coincidence of the profiles of the theoretical and observed reaction rate constants (Fig. 7).

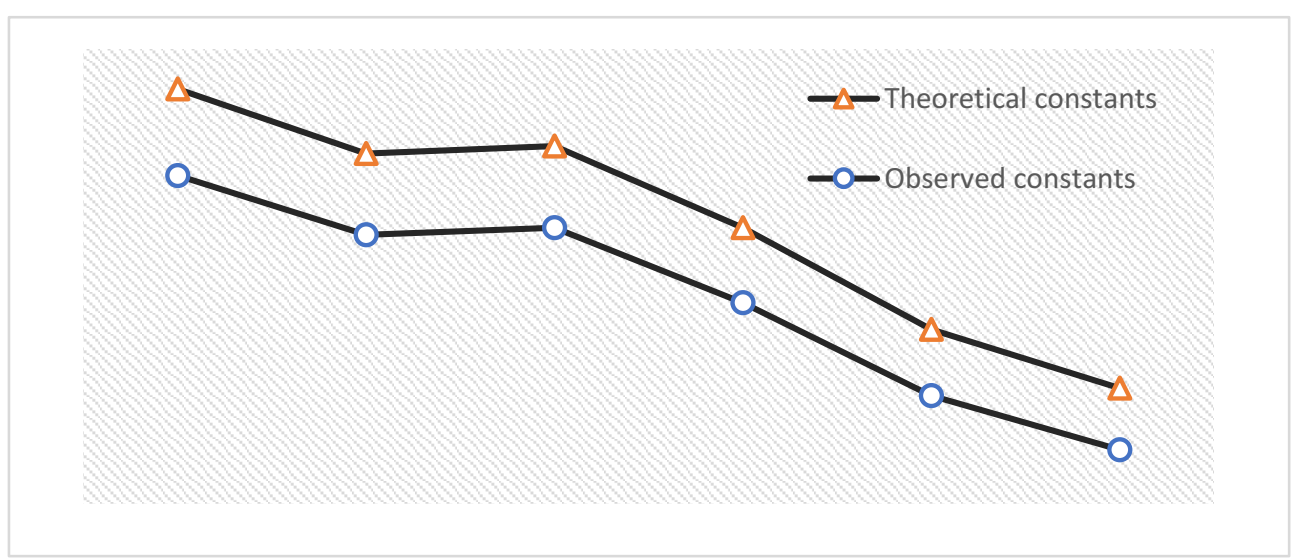

Fig. 6. Comparison of the profiles of the first-order reaction rate constants.

\subsection{Scale model study}

With the use of the presented installation (Fig. 4), the scaling of the process of destruction of dimethoate in a model solution of rinsing water in a volume of 5 liters was carried out. A contaminated solution is fed into the column through the rinsing water pipeline (1). The rinsing water is pre-controlled for the quantitative pollutant. A concentrated alkali solution (3) is fed into the alkaline chamber (2) and stirred with a paddle mixer (4). Then the mixture is exposed in a settling chamber (5). At the next stage, the resulting solution is transferred to the peroxide hydrolysis chamber (6), where a freshly prepared solution of the peroxide anion source and the substitution activator is fed through the pipeline (7). After thorough mixing, the solution is re-exposed in the settling chamber (8). At this stage, it is necessary to periodically monitor the degradation of dimethoate in the system. The revision period was 60 minutes. When satisfactory analysis results are obtained, the solution is transferred to the neutralization chamber (9). A citric acid solution is fed into the same chamber to neutralize excess alkali. 
Table 8. Observed rate constants for first-order reactions

\begin{tabular}{|c|c|c|c|c|}
\hline Sample & Peak area, c.u. & Peak area av, c.u. & $\begin{array}{c}\text { Relative Standard Deviation, } \\
\%\end{array}$ & $\begin{array}{c}\text { Concentration, } \\
\text { ppm }\end{array}$ \\
\hline \multirow{2}{*}{ Standard } & 5066019 & \multirow{2}{*}{5077335} & \multirow{2}{*}{0.32} & \multirow{2}{*}{-} \\
\hline & 5088651 & & & \\
\hline \multirow{2}{*}{ Model solution } & 14211 & \multirow{2}{*}{14224} & \multirow{2}{*}{0.13} & \multirow{2}{*}{2765} \\
\hline & 14237 & & & \\
\hline \multirow{2}{*}{$60 \mathrm{~min}$} & 214 & \multirow{2}{*}{217} & \multirow{2}{*}{1.74} & \multirow{2}{*}{42} \\
\hline & 220 & & & \\
\hline \multirow[b]{2}{*}{$120 \mathrm{~min}$} & 72 & \multirow[b]{2}{*}{71} & \multirow[b]{2}{*}{1.28} & \multirow[b]{2}{*}{14} \\
\hline & 72 & & & \\
\hline
\end{tabular}

Using formula (6), the value of the observed reaction rate constant was calculated. For the averaged process $k_{i}^{f}=2.55 \times 10^{-3} \mathrm{~s}^{-1}$. The activity index of hydrogen ions in the samples from the settling chamber (8) is 10.2-10.6. Subsequently, neutralization decreases to 7.4-7.6. Based on the data obtained (Table 8), the decontamination time of a contaminated solution with a dimethoate content of $\approx 3000 \mathrm{ppm}$ to a level below the limit of quantitative determination ( $15 \mathrm{ppm}$, according to validation characteristics) is 120 minutes.

The results obtained in this study confirm the significant decontamination properties of the proposed decontamination system.

\section{Discussion}

The kinetic parameters of dimethoate destruction indicate the low activity of hydrogen peroxide in the dimethoate decomposition reaction. The predominant contribution to the degradation reaction is made by hydroxyl ions (Table 6). The contribution of $\mathrm{OH}^{-}-$anions is more than 650 times higher than the activity of hydrogen peroxide, although its activity cannot be neglected. The observed reaction rate constant (Table 7) is almost tenfold higher than the theoretically calculated. The profiles coincidence of the graphs of changes in these constants shows the reliability of the results of the experiment and the scaling of the technological process. It should be noted that the observed reaction rate constant (in time of scaling the process) is 2 times lower than the expected value, which indicates the need to optimize the technological process. At the same time, the result obtained in this experiment showed a low variability of the chemical reaction, the stability of the value of the indicator of the activity of hydrogen ions. The value of the observed reaction rate $k_{i}^{f}=2.55 \times 10^{-3} \mathrm{~s}^{-1}$ in the course of scaling only confirms the effectiveness of the proposed method of purification of rising water in industrial use.

Extremely low concentrations of dimethoate, below the detection limit (4.5 ppm), are significantly less residues that can be released into the environment compared to the classic general methods used today (Table 3). The proposed industrial installation (Fig. 4) for the destruction of rising water is not an obstacle to industrial implementation, since it is a Neibell column with minor technical changes. Such an installation can be designed for any volume of utilized waste and does not require special operating skills. Decontamination reagents such as cetylpyriinium chloride, boric acid, potassium hydroxide and hydrogen peroxide are low cost and readily available. Any other suitable compound can be used as a source of hydroxyl $\mathrm{OH}^{-}$-anions. 
The introduction into active operation at industrial enterprises of the proposed method of decontamination of wastewater will reduce the cost of disposal. In addition, it will reduce the negative impact of disposal products on the environment. Subsequent handling of decontamination solution residues can be carried out by evaporation and disposal of the safer dry residue.

\section{Conclusion}

Researchers were the first to assess the effectiveness of chemical decontamination systems for the destruction of dimethoate. The industrial technology of cleaning wastewater from pesticide residues was tested and the residual content of toxic substances after decontamination was analysed. For the first time, industrial equipment was designed and tested for decontamination of wastewater directly at the place of its formation.

Researchers have confirmed the effectiveness of the proposed system for neutralizing dimethoate in wastewater by calculating kinetic factors.

1. The activity of systems based on alkali and hydrogen peroxide was confirmed in the presence of an activator and a micelle-forming component as a deactivator of the organophosphorus pesticide dimethoate. It was found that the observed reaction rate constant significantly exceeds the theoretical one. The profiles of the graphs of their changes coincide, which confirms the correctness of the results obtained.

2. The slope of the graph of the change in the reaction rate constant indicates the possibility of the destruction of dimethoate to lower concentrations.

3. The described technological process, aimed at the degradation of dimethoate in rinsing waters, has significant efficiency $\left(k_{i}^{f}=2.55 \times 10^{-3} \mathrm{~s}^{-1}\right)$. This significative can be increased by optimizing the technological scheme. Residual contents after destruction are at the limit of quantitative determination or below it $(\leq 15 \mathrm{ppm})$. This indicator is an order of magnitude lower than the values of emissions of existing disposal methods.

4. The given engineering solution based on the Neibel extraction column can be easily implemented into the technological lines of enterprises for the production of plant protection products. The reagents used in the process of deactivation of dimethoate are generally available and can be replaced by compounds with the same physicochemical properties.

\section{References}

1. Y. Yurumez, M. Cemek, Y. Yavuz, Y.O. Birdane, M.E. Buyukokuroglu, Biol. Pharm. Bull., 30, 490-494 (2007).

2. Enviromental Management Tool Kit for Obsolete Pesticides. (FAO Persticide Disposal Series, 12)

3. http://www.fao.org/faostat/en/\#data [05.03.2021]

4. DIMETHOATE. O, O-dimethyl S-methylcarbamoylmethyl phosphorodithioate. Fao Specifications And Evaluations For Agricultural Pesticides

5. T. J. Centner, J. Env. Quality, 27(4), 736-742 (1998).

6. C. Wilson, C. Tisdell, Ecological Economics, 39(3), 449-462. (2001).

7. R.L. Ridgway, J.C. Tinney, J.T. MacGregor, N.J. Starler, Environmental Health Perspectives, 27, 103-112 (1978).

8. M. Hattab, A. Ghaly, J. of Env. Protect., 03, 431-453 (2012).

9. N.E. Kowal, H.R. Pahren, Water Pollution Control Federation. 54(6), 677-68 (1982). 
10. C.V. Hall, J. Baker, P. Dahm, L. Freiburger, G. Gorder, Safe Disposal Methods for Agricultural Pesticide Wastes. (US Environmental Protection Agency, Municipal Environmental Research Laboratory, Cincinnati, 1981)

11. W.L.Winterlin, S.R. Schoen, C.R. Mourer, Treatment and Disposal of Pesticide Wastes, ACS Symposium Series, 259, 97-116 (1984).

12. G.A. Junk, J.J. Richard, P.A. Dahm, Treatment of Pesticide Wastes, ACS Symposium Series, 259, 125-154 (1984).

13. P.C. Kearney, Q. Zeng, J.M. Ruth, ACS Symposium Series, 259, 195-209 (1984)

14. C.J. Somlich, M.T. Kearney, S. Elsasser, J. Agr. Food Chem., 36, 1322- (1988).

15. A.S. Felsot, K.D. Racke, D.J. Hamilton, Reviews of Envi- ronmental Contamination and Toxicology, 177, 123-200 (2003).

16. B.J. Alloway, D.C. Ayres, Water, Air and Soil Pollution 102(3), 216-218 (1997).

17. D.A. Oberacker, Pesticide Waste Disposal Technology, (US Environmental Protection Agency, Noyes Data Corporation, 1988).

18. B. Adebona, A. Shafagati, E.J. Martin, R.C. Chawla, Waste Management, ACS Symposium Series, 510, 63-77 (1992).

19. K. D. Racke, J.R. Coats, Enhanced Biodegradationof Pesticides in the Environment (American Chemical Society, Washington DC 1990).

20. A. Mokrini, D. Oussi, S. Esplugas, Water Sci. and Techn., 35(4),95-102. (1981).

21. G.R. Peyton, W.H. Glaze, Photochemistry of Environmental Aquatic Sys-tems, ACS Symposium Series. 327, 76-88 (1987).

22. W.H. Glaze, Env. Sci. and Techn., 21(3), 224-230 (1987).

23. J. Inacio, C. Taviot-Gueho, C. Forano, J.P. Besse, Applied Clay Science. 18(5-6), 255 264 (2001).

24. M. Ahmaruzzaman, V.K. Gupta, Ind. and Eng. Chem. Res., 50(24), 13589-13613. (2011).

25. M. Akhtar, S.M. Hasany, M.I. Bhanger, S. Iqbal, Chemosphere, 66( 10), 1829-1838 (2007).

26. M. Alhattab, A.E. Ghal, J. of Env. Prot., 3(2), 150-163 (2012).

27. F. Li, Y. Wang, Q. Yang, D.G. Evans, C. Forano, X. Duan, J. of Hazardous Materials, 125(1-3), 89-95 (2005).

28. F.K. Pfaender, M. Alexander, J. of Agr. Food Chem., 20(4), 842-846. (1972).

29. M. Tang, M. You, Microbiol. Res., 167(5), 299-305. (2011).

30. L.N. Vakhitova, N.V. Lakhtarenko, A.F. Popov, Theor. and Experim. Chem., 51(5), 307-313 (2015).

31. V. Vasylenko, Modeling of solid hydrogen peroxide based decontamination systems (2018). 